\title{
Spaces of Change: Arab Women's Reconfigurations of Selfhood through Heterotopias in Manal al-Sharif's Daring to Drive
}

\author{
MOUSSA POURYA ASL \\ School of Humanities, Universiti Sains Malaysia, 11800 USM, Pulau Pinang, Malaysia \\ moussa.pourya@usm.my
}

Published online: 20 October 2020

To cite this article: Moussa Pourya Asl. 2020. Spaces of change: Arab women's reconfigurations of selfhood through heterotopias in Manal al-Sharif's Daring to Drive. KEMANUSIAAN the Asian Journal of Humanities 27(2): 123-143. https://doi.org/10.21315/kajh2020.27.2.7

To link to this article: https://doi.org/10.21315/kajh2020.27.2.7

\begin{abstract}
Stereotypically depicted as unresisting and passive victims of oppressive power, Saudi women are generally considered as unable to effect changes to the patriarchal sociopolitical status quo. This article studies the Saudi woman life writer Manal al-Sharif's Daring to Drive (2017) to demonstrate the various ways in which the subjugated women instigate social transformations by resisting against the prevailing male dominated system. To this end, Michel Foucault's theories on "other spaces" are employed to examine the function of spatial modalities in the workings of the dynamics of power. It is argued that the portrayed female subjects re-construct, re-experience and re-utilise different spaces to re-invent new identities and galvanise alternative ways of life. The analysis reveals that within the emancipatory space of the Internet, Saudi women produce heterotopias of transgressions, resistance and utopianism to unsettle the prescribed boundaries of malefemale relations, protest against the impositions of gender performance in public spheres and creatively re-imagine an alternative, desirable order of things. Hence, the study arrives at two conclusions: first, Saudi women's individual urgency for self-transformation have generated major social changes and ideological reconfigurations, resulting in many of the recent democratic developments in the country; second, space is not merely a normalised and rationalised construct, but can function as a normalising and transformative force at the same time.
\end{abstract}

Keywords and phrases: heterotopia, transformation, Saudi women, Michel Foucault, Manal al-Sharif

\section{Introduction}

In conjunction with the profound social, political and cultural transformations that have occurred in the Arab world since the beginning of the present century, the long-standing socially-marginalised status of women in Saudi Arabia has 
similarly undergone remarkable changes. However, Saudi women's significant contribution to the changes, not least their active role in re-ordering the masculine dominated gender relations and boundaries, have been systematically overlooked from both local and global accounts of democratic developments. The widespread disinterest in Arab women's activism stems from the traditional stereotype that Middle Eastern women in general and Saudi women in particular are unresisting, innocent and docile and thus either are unable to or are apathetic to effect changes to the socio-political status quo. In the West, their activism is written out to maintain the Orientalist image of Muslim woman as helpless and powerless who needs to be saved by white men from misogynistic Muslim men (Asl 2019a). And in Saudi Arabia, they are identified with a similar passivity for two main reasons. First, the idea is in tandem with the traditional image of Arab woman as dutiful, obedient and unassertive which the male clerics have endorsed based on a literal interpretation of Islam. And second, it allows the male authorities to take the credit for any social transformation that is wrought by women themselves (Hamdan 2012, 201) and in so doing, claim that their monarchy is progressive and liberal.

Notwithstanding the systematic omission of Saudi women from narratives of political participation (Sassoon 2016), many Saudi women writers have recently turned to life writing - as a counter-hegemonic vehicle - to document their understated socio-political activism, express their discontent, claim for equal rights and inspire more developments. Over the past two decades, Saudi women writers like Ferial Masry, Rajaa Alsanea, Rania al-Baz, Sami Alrabaa, Ensaf Haidar and Manal al-Sharif - to name a few - have attempted to speak out through autobiographical writings and shake up the stereotypes by demonstrating the complexities of their everyday life experiences and struggles. The life narratives, however, have largely been criticised for having little to do with correcting the existing misperception of Arab women's lack of agency as they are more preoccupied with selling the "story of brutal oppression, followed by liberation and the realisation of Western values", to the West (Mendola 2009, 222). The suspicion was fuelled by the sudden surge of works in the aftermath of $9 / 11$ events in 2001, raising concerns that the narratives are produced to advance the propagandist discourse of "war on terror" and rationalise the West's intervention in the region.

The present study aims at problematising the twofold assumption that underpins the general view of Saudi women, namely: they are passive and powerless victims subject to annihilating patriarchal practices and structures and that their autobiographical writings are equally homogenising and annihilating. Both assumptions, according to Third World feminism, homogenise and systematise 
"the experiences of different groups of women" in the Arab world and in Saudi Arabia (Mohanty 2003, 40-41) and in so doing erase all the subtle nuances of women's resistant experiences. In this regard, the present article develops a twofold argument: First, women in Saudi Arabia have never been utterly silent nor purely passive but have struggled constantly to maximise their rights and negotiate their "power and space" (al Fassi 2016, 189); second, the Saudi women's sense of self as portrayed in autobiographical writing is not static, but a developing process of reconfiguring individual and collective forms of selfhood, of transformation and of improvement. From a postcolonial and Third World feminist perspective, pursuing this line of argument requires reading the life narratives anew with a specific methodology and analytic strategy, because the existence of Saudi women's life stories "in itself is not evidence of decentering hegemonic histories and subjectivities. It is the way in which they are read, understood and located institutionally that is of paramount importance" (Mohanty 2003, 77-78, emphasis added). Besides, the task of contesting the prevailing assumptions, according to Third World feminists, should not be "limited to the exposure of macro-grids such as Orientalism" but also critique micro-spaces that are produced by the prevailing male-dominated system and contested by resistant women at the same time (Moore 2008, 100). Based on this premise, gendered spaces should be thought of "less as a geography imposed by patriarchal structures and more as a social process of symbolic encoding and decoding" that creates homologous spatial, symbolic and social orders (Blunt and Rose 1994, 3).

This article focuses on Manal al-Sharif's Daring to Drive: A Saudi Woman's Awakening (2017) to examine the various ways in which the subjugated female characters actively use different spaces, either at a micro or macro level, to reconfigure individual and collective forms of selfhood. Daring to Drive recommends itself for such a study as it is a characteristic example of the decoding and recoding of gendered spaces. Its subject matter revolves around issues related to Saudi women's daily struggles to renegotiate the established meaning of public space so that they gain equal right to occupy it and participate in its activities such as driving. The narrative is enriched by the female narrator's eye witness accounts of Saudi women's reconfiguration of spaces to shackle the traditionally prescribed male-female relations and to progress women's status in society from confinement to liberation. In doing so, the book shows an understated side of women in Saudi Arabia in which a young Muslim woman stands up to a kingdom of men - and wins. In mapping spaces of female resistance and agency in al-Sharif's life story, this study seeks to demonstrate the portrayed Saudi women's active participation in resisting against normalised social values and constraints-e.g., wearing traditional hijab and property, employment and mobility rights - and in inducing 
social transformation by re-constructing, re-experiencing and re-utilising different spaces.

Foucault $(1986$; 1999) offers a sophisticated framework for a specific way of "reading", "understanding" and "locating" al-Sharif's work. His theories on "other spaces" underline the relation between space and power, shedding light on how different spaces can be strategically used by subjugated individuals and communities as sites of social struggle and of production of alternative realities. For Foucault, space has a transformative power and subjects can actively use heterotopias or alternate spaces, as counter-hegemonic sites to protest against the status quo and induce micro- and/or macro-changes. In this regard, the notion of heterotopic space adopts an anti-essentialist position on identity, approaching it not as a "set of fixed characteristics that an individual "possesses"" (Zembylas and Ferreira 2009, 2), but as a complex and fluid construct that could be refashioned, altered and transformed. Foucault's conceptualisation of power in relation to heterotopic spaces as transformative, positive and productive is of particular relevance to Third World feminists, as it allows different groups of subjugated women and individuals to be "conceived as agents, as social actors, [and] as desiring subjects" (Mohanty 2003, 99). This specific strategy of reading focuses on women as active decision makers who are not only able to self-critique and self-evaluate but also competent to "organise collectively against their oppressors" (Mohanty 2003, 72). It also resonates with key issues in Third World feminist studies that oppressive female spaces are not "ahistorical, fixed and absolute" (Hamam 2014, 5), but can be contested, reconstructed and re-deployed as spaces of agency.

Hence, in exploring the condition of Saudi women - as portrayed in Daring to Drive - in the light of Foucault's notion of heterotopic spaces, this study underscores the significance of space in interrogating existing social norms and gendered hierarchies; and challenges the problematic assumptions about and representations of Saudi women. By problematic I refer to the conventional public and critical reviews that easily recognise Arab women as passive, unresisting objects of male oppression who are unable to overthrow the status quo. The study of al-Sharif's life-narrative from a Foucauldian perspective is important because it helps to correct the essentialising misconception that Arab women are "completely secluded, passive and domesticated beings" (Golley 2007, 526). More specifically, it unravels the distinctive ways in which a particular group of Saudi women actively manipulate spatial relations to re-imagine new ways of ordering, re-construct existing forms of knowledge, re-invent new identities and galvanise alternative ways of life. 


\section{Manal al-Sharif and Her Story of Change}

Born in Islam's holiest city of Mecca in Saudi Arabia, Manal al-Sharif's (b. 1979) childhood was formed by the spread of religious fundamentalism. In her 20s, however, the privilege of academic education at King Abdulaziz University together with a unique employment opportunity at Saudi Aramco helped to gradually transform her from a fundamentalist Muslim into a moderate and liberal observant. The change was further accelerated by an unhappy early marriage that ended in an unfair divorce court which gave the full legal custody of their son to the husband in accordance with the strict guardianship laws upheld in her country. The painful experience, as illustrated in the subtitle of her memoir, marked as a watershed moment in her realisation of the existing contradictions in the dominant notions of justice and rules as well as of the double standards in male-female relations in Saudi Arabia. In the aftermath of this "awakening", al-Sharif began to express feminist concerns and became an active critic of the Saudi government. In 2011, she helped to start a women's right to drive campaign which drew global attention to the Saudi government's degrading treatment of women, ultimately leading to incremental changes in the country's body of laws concerning women. Al-Sharif's driving campaign and social activism are important as they represent "how seemingly small acts of deviance may provoke much wider changes in a society" (Wolf 2019, 75). Known as an ardent Saudi Arabian feminist, she was finally named one of the 100 Most Influential People of 2012 by the Time magazine.

Even though al-Sharif had already discussed aspects of her life in many public speeches and interviews at United Nations, Harvard University, WIRED summit, the Oslo Freedom Forum and a "Technology, Entertainment and Design" (TED) talk, she documented the story of her social activism in an autobiographical book titled Daring to Drive, published in 2017. Written in English, the book is largely a chronicle of the struggles and ordeals that she had to undergo in her campaign for Saudi women's societal mobility. It offers original insight into the male-centred cultural impositions that women in Saudi Arabia experience every day. But the power of the book lies in its unearthing the female narrator's progression from unquestioning compliance with social conventions to fierce resistance against their inherent prejudices. Despite the individuality of the change and the awakening brought about by painful experiences, the final chapter of the memoir titled "The Rain Begins with a Single Drop" reflects the collectivity of the experiences and of the fight for feminist causes. It demonstrates how a female subject's individual urgency for change generates macro-transformations at political and ideological levels. 


\section{Narratives of Change: Developments, Departures and Receptions}

The radical transformations in the socio-political reality of Saudi Arabia that have occurred over the past two decades have also been reflected in the remarkable developments in the country's cultural and literary productions by women at both "quantitative and qualitative levels" (Algahtani 2016, 31). A new generation of women writers have turned to life writing to draw to centre the voices of the periphery. In the Arab context, where women are conventionally expected to be reticent, prudish and self-abnegating, autobiographical narrative discourse has always been the privilege of the masculine (Kholoussi 2019, 287-288). The advent of the Internet together with the unrestricted access to global publishers have helped Arab women to bypass the hurdles of social and institutional censorship and articulate and reconfigure their individual and collective selfhood through life writing. Unlike the conventional life narratives in which the Arab female subject was a "monolithic and predetermined construct", contemporary life accounts by Arab women show the autobiographical subjectivity of female Arab "in the state of perpetual transformation through time and space" (Anishchenkova 2014, 4-26). Saudi women writers have implemented different strategies in both content and style to "defy dominant centres and narratives" (Hamam 2014, 22). In their stories, the female narrators transcend the authorial I and connect their individual selfhood to collective identity by portraying Arab women as active participants in socio-political issues. In doing so, the narratives "re-scribe diverse female voices, ...create alternative, resistant female spaces...[and] inspire change" in the society (Hamam 2014, 11). In addition, for Saudi women life writers, recording their life stories in English and reaching out to a global audience are "sign[s] of liberation from traditional values and restrictions" (Nash 2007, 154). Al-Sharif $(2017,225)$ acknowledges this sense of liberation particularly in the chapter "Driving while Female", when her socio-political struggles for "change in the country" gave her the feeling that "we were now in the driver's seat of our own destiny".

In like manner, Daring to Drive marks a radical departure from the tradition of literary narrative in its content and style. At a thematic level, it disrupts the Orientalist conventions by showing Saudi "women not only as 'objects of oppression' but rather as social actors and sometimes as manufacturers of their own lives" (Golley 2014, 164). It also contests Arab male standards by providing the female narrator with a space to "openly talk about taboo aspects of autobiographical subjectivity, such as family relationships, sexuality, political activity, [and] unconventional religious beliefs" (Anishchenkova 2014, 10). At a technical level, the use of English language as the medium of expression represents a similar departure in two ways. First, it is a strategic choice that serves to interrogate Arab literary canon and tradition as an Arab male prerogative. 
It is noteworthy that notwithstanding the long history of biographies and autobiographies in Arabic language and civilisation, "[p]olitical memoirs in the Arab region rarely include biographies written by and about, women" (Sassoon 2016, 14). Second, the language is used to write back and correct Western misconception of "East as exotic" and of Oriental Saudi woman as the passive object of repression (Suyoufie 2008, 229). Therefore, al-Sharif's use of English as a "means of communication with the West" does not replicate the stance of Western "ethnographers who seek knowledge of what they usually see as (inferior) 'other' culture" (Golley 2003, 91), but seeks to " take the other lives of women' into account" (Bosch 2008, 142, emphasis added) and in so doing clarify some of the misconceptions about Saudi women. Thus, Daring to Drive engages itself in a double struggle: "internally against the old religious, social and economic order; and externally against European colonisation" (Golley 2007, 529).

Nevertheless, the constructive ways in which contemporary Saudi women's life writings reflect their socio-political activism and defiance have mainly remained unexplored (Mustafa and Troudi 2019, 138). Rather, there is a general tendency in the existing body of literature to censure the works for their reductionist portrayal of Muslim women as weak, powerless and passive victims of misogynistic Islamic tradition (al-Ahmadi 2011; al-Sudairy 2017; Lim 2018). These critics believe that the majority of the narratives misleadingly and ahistorically depict Saudi woman as "an ignorant, oppressed" subject who is submissive and "locked into restrictive traditional roles" and who is unable to demand and fight for her rights (al-Ahmadi 2011, 151; al-Sudairy 2017, 3). To them, the contemporary eye-witness accounts by or about Arab women offer a limited view about the condition of women in Middle East as they heavily rest on the widespread "Orientalist" stereotypes primarily the notion that Muslim women are passive victims of patriarchal authoritarianism. The persistent stereotypes reflect a long-standing limited understanding of gender relations and their involvement with social and political factors in Muslim and Middle East countries. Totah (2017) and Tsujigami (2018) situate the works within the context of recent democratic changes in the country to argue that their structured and monolithic depictions of Saudi women as purely passive objects only serve to credit the male authorities with any emancipatory and upward mobilisations that take place in the social sphere. Part of the harsh criticism against the accuracy of the representations proves to be valid considering the fact that many of the written testimonies are given by Western women-e.g., Laube (2010), Petrushevskaya (2013) and Sassoon (2014) — either as first-hand eye witnesses or ghost-writers for native informers. These narratives are fraught with exaggeratedly dim depictions of women in Saudi Arabia as passive victims of state-sanctioned gender segregation. 
The scathing attack on the majority of Arab women's life writings as discursively reductive and homogenising reaffirms the need, recognised by postcolonial and Third World feminists, for a distinctive strategy of "reading", "understanding" and "locating" Third World women's life stories to appreciate their "differences and specificities" (Hamam 2014, 13). The new analytic strategy, according to Mohanty (2003, 233-234), which should focus on the daily experiences of marginalised women and "the micropolitics of" their antipatriarchal struggles, can illuminate "the macropolitics of global restructuring. It suggests the thorough embeddedness of the local and particular with the global and universal". Therefore, in the analyses of Saudi women's autobiographical writings, there is a growing need for a more inclusive approach to "unveil the 'research invisibility' of Saudi women", i.e. to avoid merely focusing on "suppressed" women but to study politically active females and their self-transformative realisations as well (Mustafa and Troudi 2019, 138). Hence, the proposed Foucauldian framework in this paper is a timely attempt to explore, using al-Sharif's memoir, the female author's active engagement in self-liberation from the restricting boundaries of her sociocultural environment.

Even though the existing literature on al-Sharif's Daring to Drive is very limited, it is widely acknowledged by critics and the public that the book documents a Saudi woman's particular state of activism and transformation (Begos 2017; Faruqi 2017; Haragos 2019; Wolf 2019). Saudi women writers like al-Sharif, as Alenazy $(2017,16)$ aptly stresses, have directly employed literary spaces "to challenge and contest the asymmetrical gendered power relations" in their attempts to redefine their selfhood and transform their social status. Her life-story of Saudi women activists struggling to mobilise a campaign to lift the ban on women driving reflects the fact that women in Saudi Arabia do not necessarily see themselves as passive victims who need to be saved by others (Asl 2018; 2019b). Rather, as is demonstrated throughout the work, they use different techniques and tactics to challenge patriarchy directly and subvert the established norms on their own terms. Daring to Drive has received similar public reception. Begos (2017) notes that the memoir is a "story of one woman's battle for equal rights" which shows Saudi women have "dreams and fears much like" other people. And in like manner, Faruqi (2017) praises the way it bears witness to "how women in Muslim countries are helping change their culture, one step at a time".

Notwithstanding the positive critical reviews and favourable public reception, the complexity and dynamism of female subjectivities - in creating "alternative, resistant female spaces" (Hamam 2014, 11) - as portrayed within the narrative have scarcely been studied. The present study has been carried out to fill the gap by offering a distinctive strategy of Foucauldian "reading" and examining 
the image of an active Saudi woman who is creatively using different spaces to interrogate patriarchal norms and redefine new ones. In doing so, the study contributes to recent Third World/South feminist scholarship - or methodology and analytic strategy - that calls for "the definition and recognition of the Third World [woman] not just through oppression but in terms of historical complexities and the many struggles to change these oppressions" (Mohanty 2003, 501). Unless one understands the relationship between space and power, one would not be able to appreciate the degree of micro- and macro-changes brought about in Saudi culture and politics; hence, the following section on Foucault's theories of power and space.

\section{Foucault's Theories on Heterotopias as Spaces of Transformation}

Throughout his works, Foucault underlines the crucial role of spatiality in human relations and identity formations. In "Of Other Spaces" (1986, 23), he elaborates that "the anxiety of our era has to do fundamentally with space" because when placed within the framework of power and politics, space works as a site of constant tension between power(s) and resistance(s). This means that space has two opposing, but interrelated functions. First, it works, as in the case of a panoptic sphere, "to transform individuals: to act on those it shelters, to provide a hold on their conduct, to carry the effects of power right to them, to make it possible to know them, to alter them" (Foucault 1995, 172). Here, space is conceptualised as both an object and a means of governmentality as it provides the material conditions through which practices of power are exercised. Therefore, space is constantly and systematically controlled, regulated and normalised by the hegemonic power with the aim of regulating individuals and populations.

Yet, Foucault $(1986,24)$ also reminds us that there are other places in every society that allow the production of alternative realities in contesting and inverting the existing social spaces. He refers to such counter-sites as heterotopias, which are emancipatory, temporary and clandestine in nature. Located in the real space, heterotopias are "enacted utopias" that open up a line of subjectivity by offering a temporary passage away from power. Of the numerous examples of counterspaces - cemeteries, brothels, prisons, museums, theatres, gardens, asylums, carnivals and fairs - that Foucault provides, children's imaginative games best illustrates the concept. In children's inventive plays, which may be an ancient fairy-tale castle or a futuristic space ship, the actual "real" play area turns into an imaginary space that shifts across different spaces and temporalities. The heterotopic space or the imaginary world in the case of kids, provides subjects with an opportunity to escape from the ruling rationalities, to think differently and to contest the unwelcome impositions that are justified in all the other spaces. 
As such, heterotopias exist "outside of all places" and are "absolutely different from all the sites that they reflect and speak about" (ibid.). Notwithstanding their fundamental difference from other places, the emancipatory sites have an essential quality of being in direct but contradictory relation with all the other actual spaces. Heterotopias, remarks Johnson (2006, 87), "light up an imaginary spatial field, a set of relations that are not separate from dominant structures and ideology, but go against the grain". In this connection, heterotopias have two particular functions: illusion or compensation. The latter refers to the other spaces that differ from all the existing social spheres, not by disrupting but by compensating for and perfecting all the real space's flaws and imperfections. Heterotopias of compensation, as Foucault $(1986,27)$ elaborates, "create a space that is other, another real space, as perfect, as meticulous, as well arranged as ours is messy, ill constructed and jumbled". The former function, however, formulates "a space of illusion that exposes every real space" (ibid.). In other words, heterotopia of illusion is a subversive one that aims to destabilise or even invert the governing principles, norms and conventions and produce instead a new ordering.

The significance of a heterotopic space as a spatio-temporal reality is two-fold. First, it makes the disruption and re-formulation of the dominant orders possible. The heterotopic spaces, according to Hetherington (1997, viii), "organise a bit of the social world in a different way to that which surrounds them. That alternative ordering makes them out as Other and allows them to be seen as an example of an alternative way of doing things". In being different and other spaces, heterotopias disrupt the dominant discourse of power and make possible alternative modalities of ordering. Thus, heterotopias can be defined as "counter-hegemonic spaces that exist apart from 'central' spaces that are seen to represent the social order" (ibid., 21)

Second, such an understanding of heterotopias as sites of resistance and transformative political practices underscores the constructive role of individuals in disrupting the imposed definitions of selves and creating new identity formations. In "Space, Knowledge, Power", Foucault clarifies that the flow of power is not entirely controlled by the existing real social spaces, but is somewhat influenced by the practices of those who occupy the space: "If one were to find a place and perhaps there are some, where liberty is effectively exercised, one would find that this is not owing to the order of objects, but, once again, owing to the practice of liberty" (Foucault 1999, 135). The marginalised subjects have the will to protest against normalisation by interrogating the dominant conventions through heterotopic spaces. In this sense, both space and identity are interpreted as constructs that reflect the dialogic processes of their "becoming". This relational quality of heterotopic spaces, which "marks territories of struggle, 
rather than fixed localities" (Zembylas and Ferreira 2009, 2), similarly signifies a dynamic anti-essentialist notion of identity by opening up possibilities for selftransformation through transgressive practices within heterotopic spheres.

Foucault's notion of heterotopia and its application as a reading strategy enables the development of the main argument of the present study concerning women's situation in Saudi Arabia. Analysing al-Sharif's Daring to Drive from the framework of heterotopic spaces acknowledges Saudi women's constructive role in re-defining their identities by problematising, excavating and exposing constraints of the dominant culture. The proposed analytical framework helps us to understand the various ways in which Saudi women creatively produce autonomous, temporary and at times clandestine spaces within public and private spheres to order new social practices and free themselves from the shackles of patriarchal values and norms.

\section{Spaces of Transformation in Daring to Drive}

Women in the Kingdom of Saudi men, writes al-Sharif $(2017,89)$, are subjected to various modes of disciplinary power by constant regulation of space and time. Throughout their lives, Saudi women pass through two formative stages: "First, as young girls, they are supervised and monitored; then, as adult women, they are controlled and judged". As such, the regulating power is exercised on women in both private and public spheres of the society with the aim of producing docile bodies. Docility, in the case of Saudi women, means obedience, submissiveness and passivity. Within the domestic sphere, the regimentation to forge docile bodies is applied by the father figure, who acts as the surrogate of the hegemonic power. Within the public sphere, women are further trained by disciplinary institutions such as schools and universities, which are controlled by religious institutions. The significance of the school as a dystopian or undesired, space wherein microphysics of power are exercised is two-fold. First, it is the regulatory power of the girls' school that evokes docility by monitoring and appropriating the "various kinds of spaces required for one to manage and define one's self" (Leib 2017, 192) and makes it an epitome of a dystopian locality. Silverman (1980, 171-173) defines dystopia as "a place of constraint, despair and unhappiness" that "achieve[s] order through enforced accord and agreement". The girls' school in Saudi Arabia are directly governed by the hard-line Salafist ideology ${ }^{2}$ to ensure the inculcation of mainstream doctrines. ${ }^{3}$ Within these dystopian spaces, al-Sharif writes (2017, 75-76), "[t]here was a suffocating control over everything. Independent thought was discouraged; ... [T] he manner in which we were taught molded and subjugated us in such a way that we became domesticated and tame". Thus, the school is portrayed as the negation of a desired good place, an anti-utopia 
wherein the girls' visions, hopes and subjectivities are altered with constraints, intimidation and ordeals. Associated with the female subjects, the girls' school is actually a nowhere, a dystopian non-existent place that "had no names... The female students were as invisible as their schools" (ibid., 66). In this manner, the shape of dystopia-i.e., the undesired space replete with repressions, exclusions and oppressive authority-ranges from the private to the public spheres.

Afflicted with despair and unhappiness at both domestic and social spheres, the portrayed female characters in al-Sharif's narrative recourse to heterotopic discourses to interrogate, disrupt and escape from the present dystopian spaces, rather than simply inhabit them. They seek to generate and re-imagine new, albeit temporary, discursive realities to realise a utopian model of life-i.e., an ideal, well-defined and well-crafted reality. For al-Sharif and her fellow Saudi women activists, one 'other' space that allows for the construction of a heterotopia is the cyberspace, which is often "envisioned as a technological utopia" (Hetland 2012, 3). Unlike the sovereign power that cautions against the "evil of the Internet" and its destructive potential to pollute the "pure, extreme Salafi doctrine" (al-Sharif 2017, 131), Saudi women appreciate the emancipatory and transformative power of the online spaces. According to al-Sharif, "the advent of the Internet and later, social media" during the Arab Spring of 2011 transformed Saudi women's lives by liberating them from the fetters of Salafi-inspired radicalism (al-Sharif 2017, 133). Through the cyberspace, as we are told, women find themselves "in possession of a voice - a miraculous thing in a country where women are almost never heard" (al-Sharif 2017, 133). Twitter, Facebook, YouTube, weblogs and online media are employed not only to communicate but also to voice out their frustrations, put forward their demands and organise anti-state protests or movements. In this manner, the cyberspace becomes heterotopic as "the purposes of heterotopia change to suit the need of the moment" (Davis 2010, 667). On different occasions, the female characters actively use the virtual space to effect changes at personal and social stages. This article has identified three main purposes in using the online space as a heterotopia: first, to transgress established gendered relations and norms; second, to resist and rail against dystopian realities; and finally, to reimagine a utopian future.

\section{Heterotopias of transgression, resistance and utopianism}

The cyberspace has exerted magical effect on Saudi women's lives by offering them another place to defy conventions and shift themselves from periphery to centre. This is crystallised when al-Sharif reveals to us that Saudi girls used online platforms as a safe place "to date and exchange messages without being watched or held accountable by anyone" (al-Sharif 2017, 131). The significance 
of this defiance lies in the fact that the traditional social structure in Saudi Arabia subscribes segregation of the sexes and dictates women to act in "a strictly domestic capacity" (Hamdan 2012, 201). The interpersonal relationship between men and women and most importantly those who are not directly related to each other, is socially and religiously proscribed. Boys and girls have "existed in two entirely different worlds" insofar as girls and young women are prevented "from talking to any men at all, even the seller from whom" they buy their clothes (al-Sharif 2017, 120). Women's failure to observe such rigid taboos is seen as a rupture of the patriarchal order of things. In other words, gender-bias and male favouritism form the heterotopian realities of contemporary Saudi Arabia.

Within this context, Saudi women's socialisation with men other than their immediate family members through cyberspaces allows them to go through a heterotopian experience to rupture the normalised masculine order of things. This means that the online space offers women a way to transgress and reconstruct the formation of public, private and institutional spaces which they inhabit. It offers women a safe space to seize their freedom and explore their sexualities and gender identities. In doing so, the cyberspace presents Foucault's notion of heterotopia in the form of the motel room as a discursive reality that can be potentially in conflict with the dominant and normalised societal and religious taboo, infidelity. In the motel room, according to Foucault $(1986,27)$, "illicit sex is both absolutely sheltered and absolutely hidden, kept isolated without however being allowed out in the open". Similarly, the Internet created unconventional intimate social connection between Saudi girls and boys. Although prohibited, the practice of dating and exchanging messages takes place in a (self-imposed) transgressional heterotopia which, in Foucauldian parlance, "shelters the participant's behavior from societal view often clandestinely: a scene that society wishes neither to see nor to occur" (Dodge 2015, 321). In certain ways, this emancipatory discursive reality reflects, takes on and transforms definitional significance of what Foucault identifies as crisis heterotopias.

Heterotopias of crisis are "privileged or sacred or forbidden places, reserved for individuals who are, in relation to society and to the human environment in which they live, in a state of crisis: adolescents, menstruating women, pregnant women, the elderly, etc." (Foucault 1986, 24). Relevant examples include boarding schools, military service and honeymoon trips to which individuals are relegated to be normalised and rehabilitated by undertaking certain activities vital to their existence. These crisis heterotopias are created by the society to keep certain activities under control: for example, young men's first manifestations of sexual virility and young women's deflowering are "supposed to take place 'elsewhere' than at home", at such heterotopias of crisis (ibid.). Saudi girls turn similar states 
of crisis into a transgressional existence by virtue of excessive deviation from prevailing gender relations. In one illustrative example, as al-Sharif reveals to us, "the separation of the sexes in Saudi Arabia" led to the emergence of a "female subculture known in Arabic as boyat" at sports club of King Abdulaziz University (al-Sharif 2017, 125). ${ }^{4}$ In the absence of men, as she maintains, boyats "wore men's hairstyles, men's shirts and even men's fragrance. Each boyat had a close female friend with whom she'd walk hand in hand and from whom she was rarely apart" (al-Sharif 2017, 125). In this sense, women's only sports club works as a transgressional heterotopia-i.e., a masculinised space of femininity-because boyats transgress rather than deviate from the normalised codes of conduct for women. They transgress the standards of feminine behaviour in an excessive expression of re-formulated masculinity. Their transgressive sexual deeds are perpetrated in what Foucault $(1986,24)$ refers to as "elsewhere", as they could not be performed just anywhere. Hence, much like the online space, the sports club at King Abdulaziz University serves as a transgressional heterotopia in that Saudi women reconstruct it as "a space of illusion that exposes every real space" (al-Sharif 2017, 27). For the online space, like the sports club, the illusion is twofold, leaving the individuals with "facing a huge dilemma" (al-Sharif 2017, 126). On the one hand, both spaces exist outside real places, as "placeless place[s]" that mirror real life and experiences; on the other, they have no outside in that they are immediate and similar to "all the sites that they reflect and speak about" (Foucault 1986, 24). In other words, both the cyberspace and the sports club provide a contrast to the normalised real life and because of that, they are "socially and religiously forbidden" (al-Sharif 2017, 125) and yet, as the narrator tells us, their experiences are utopian, emancipative and transformative. Through surfing the Internet, al-Sharif (2017, 132-133, emphasis added) observes:

Gradually, I realised that the ideas I had embraced and defended blindly all my life represented a singular and highly radical, point of view. I began to question everything. I began posting in forums, discussing these radical ideas and rejecting them. ... Nothing did more to change my ideas and convictions than the advent of the Internet ... [through which] I found myself in possession of a voice - a miraculous thing.

The cited extract underlines the distinguishing quality of the transgressional heterotopia as a potential space of self-realisation and transformation. Moving out of transgressive "chat rooms" and into surfing "websites that railed against Salafi ideology" marks the transition from heterotopias of transgression to heterotopias of resistance (al-Sharif 2017, 132). If sports club or chat rooms are transgressional heterotopias that sanction Saudi women's homosexuality and their socialisation with other men, their intentional stumbling on "sites opposing Saudi regime" 
and posting anti-extremist content lead to the construction of a heterotopia of resistance.

Besides building communities and communicating with the opposite sex, Saudi women use the cyberspace to expose the present dystopian realities and rail against the rampant "repression, authoritarianism and tradition" (al-Sharif 2017, 225). Many Saudi women use Facebook and Twitter, albeit anonymously or under fake names, to pour out their complaints, organise "daily protest" and change the existing discriminatory customs (al-Sharif 2017, 201-206). In this manner, women actively utilise the online space as a heterotopia of resistance i.e., counter-hegemonic or "counter-sites, spaces in contestation of or in contrast or opposition to" other real sites (Genocchio 1995, 38). Their engagement with the construction of heterotopias of resistance is crystallised through their formation of various private and public profiles, groups and pages to interrogate prevailing sociocultural discourses and destabilise the patriarchal male-female relations. One characteristic example is the Facebook group titled "Saudi Female Employees of Aramco" which was created "to complain about anything... anywhere inside Saudi Arabia" (al-Sharif 2017, 206). Though it was a "completely underground" group, the female members found in it a temporary passage to voice out their agency, register their demands and fight for their political rights.

Yet, Saudi women's urgency for individual and collective transformations is more perfectly illustrated through their online campaign to negotiate their rights to drive. Even though there is technically no rule in the country's traffic code "saying that women cannot drive", women in Saudi Arabia have traditionally been banned from driving as it is religiously considered "haram for women to drive" (al-Sharif 2017, 209-211). The female narrator's online campaign titled "Women2Drive" is a concerted attempt to generate political awareness and bring about social, cultural and political reformations. The campaign invited Saudi women nationwide to drive on a certain day, make a video of it and upload it on the Internet. The female managers' primary goal was to "normalise the experience and show Saudi citizens that there was nothing dangerous about women driving" (ibid., 221). Here, the cyberspace functions heterotopic precisely because it provides Saudi women with an escape route from patriarchal definitions of gender performance and hence stands in contradistinction to the rest of the society in which the only acceptable behaviour for women is silence, submissiveness and obedience. On the one hand, the otherness implicated in cyberspace is used by the hegemon to demoralise its female users' political activism with the aim of suppressing their strategies of resistance. Many men, for example, 'equated the 'Women2Drive' campaign with women who were loose, sexually compromised and of weak, immoral character" and even created a Facebook page, titled "By Iqal", to urge "men to beat any 
women drivers they saw" (ibid., 213-214). For these men, the "otherness" of the cyberspace explains women's presence in the social media as a deviation, a moral corruption and "threatening" to the normative order of things. On the other hand, the contradistinction empowers marginalised women to effect democratic transformations. Women, according to al-Sharif, "want change in the country" and they are using the online space as a "way to challenge Saudi restrictions" and "to express the basic aspirations of Saudi women" (ibid., 217-225).

Clearly, Saudi women refashion the function of heterotopias to fit the need of the moment in their struggle for social transformations. Whether as a space of positive transgression or a site of counter-hegemonic practices, they utilise cyberspace to imagine a new order. In either case, their creative response to a dystopian reality, where their life is rather traumatic and disempowering, is a movement toward a utopian future - i.e., "an alternative, a liberating transformation" (Archer-Lean 2009, 4). In this sense, women use cyberspace as "a space 'in between' on a vertical axis with utopia above and dystopia below, while 'here and now' at degree zero" (Vrbančić 2015, 4). This utopian thinking is in itself highly conducive to individual and collective transformation. "Women2Drive" campaign, as also acknowledged by its female managers, may not "be seen an actual protest movement" (al-Sharif 2017, 221), but it envisions an opposite world to the dystopian present where liberation from the constraints of the given here and now is possible. "Through the Facebook posts", al-Sharif writes, "I felt connected to...people. It seemed like change might be possible. It seemed like change might be possible even for us (i.e., Saudi women)" (ibid., 207). The cyberspace is thus an "other space" that is strategically used by Saudi women for the advancement of a heterotopia constructed mainly on the utopian longing for an alternative, transformed and liberated reality.

\section{Conclusion}

According to Foucault, an individual's urgency for self-transformation can induce major social changes and ideological reconfigurations. This has certainly been a primary feature in Manal al-Sharif's Daring to Drive in which female subjects' tactical employment of heterotopic spaces as a medium of self-empowerment serves as a catalyst for structural changes at larger scales in the society. The analysis of the memoir revealed that notwithstanding the long-established stereotypical reputation of Saudi women for being silent and passive, al-Sharif's female characters develop the power to transform their prescribed identities as well as their structured societies by challenging many norms and taboos in the different spaces that they inhabit. Her female characters become increasingly conscious of the spatial relations in the operation of microphysics of power; and hence their 
active participation in re-constructing spaces in the process of self-liberation from the fetters of male authoritarianism. Throughout the work, Saudi women use heterotopias of transgressions, resistance and utopianism to effect change at the level of individual and to facilitate progress at institutional and cultural levels. Within the heterotopic space of the Internet, for example, Saudi women transgress the prescribed boundaries of male-female relations, resist against the impositions of gender performance at public spheres and creatively re-imagine an alternative, desirable order of things. The significance of these transformations is threefold. On the one hand, the female narrator's deployment of heterotopic spaces in her struggles for new mapping and remapping unsettles the prevailing understandings of Arab woman's identity as a fixed and predetermined construct. Second, her positive transgressions and public resistance reject the widespread view about patriarchal system in Saudi Arabia as monolithic and unbending. And finally, the findings underline the relevance of Foucault's spatial theories in approaching and comprehending Arab women's individual and collective identity as a highly complex construct and locating it within a macro socio-political context to highlight how its individual transformation can have a major impact on political and ideological configurations of the country. Hence, two conclusions can be made here. One, although the role of women in the making of recent emancipatory and upward mobilisations in Saudi Arabia is undervalued, Saudi women's acts of insubordination to desubjugate themselves have had a profound impact on many of the recent developments. Second, it is easy to conclude that not only space is itself a normalised and rationalised construct, but also it can be strategically used as a normalising and transformative construct at the same time.

\section{Acknowledgements}

The author is indebted to two anonymous reviewers for their valuable insights on earlier version of this manuscript. Dr Grace Chin Voon Sheong also provided challenging criticisms and much appreciated comments and suggestions. This work was supported by the short-term grant (304/PHUMANITI/6315300) from Universiti Sains Malaysia, Pulau Pinang, Malaysia.

\section{Notes}

1. Foucault $(1986,24)$ differentiates between utopia and heterotopia. Whereas the former refers to an imaginary or imagined spaces that do not have real existence, the latter refers to "effectively enacted utopias" that exist in the actual space.

2. Salafism is a radical Islamist ideology that "requires strict adherence to the most literal interpretation of Koran, believes in no other law but sharia and embraces the tenets of jihad against nonbelievers" (al-Sharif 2017, 94). 
3. According to al-Sharif $(2017,101)$, “[a] key component of our school curriculum was the doctrines of Loyalty and Disavowal. The first stage of disavowal, as we were taught, is to hate and to become an enemy of the 'infidels', in this case meaning anyone who is faithful to a religion or creed other than Islam, including atheists or anyone who follows another version of Islam, such as the Shiite sect".

4. It is noteworthy that "women's sports are banned under the Saudi code" with the exception of King Abdulaziz University (al-Sharif 2017, 124).

\section{References}

al-Ahmadi, Hanan. 2011. Challenges facing women leaders in Saudi Arabia. Human Resource Development International 14(2): 149-166. https://doi.org/10.1080/136 78868.2011 .558311

al-Baz, Rania. 2009. Disfigured: A Saudi woman's story of triumph over violence. Northampton, MA: Arris Books.

al Fassi, Hatoon Ajwad. 2016. Saudi women and Islamic discourse, selected examples of Saudi feminisms. Hawwa 14(2): 187-206. https://doi.org/10.1163/1569208612341306

al-Sharif, Manal. 2017. Daring to drive. London: Simon \& Schuster.

al-Sudairy, Hend T. 2017. Modern woman in the kingdom of Saudi Arabia: Rights, challenges and achievements. Newcastle upon Tyne, UK: Cambridge Scholars Publishing.

Alenazy, Khaled. 2017. The delegitimisation discursive strategies of women's right to drive in Saudi Arabia. PhD diss., University of Essex.

Algahtani, Noura. 2016. Defying convention: Saudi women writers and the shift from periphery to centre. Women's Studies International Forum 59(6): 26-31. https:// doi.org/10.1016/j.wsif.2016.09.002

Alrabaa, Sami. 2010. Veiled atrocities: True stories of oppression in Saudi Arabia. Amherst, NY: Prometheus Books.

Alsanea, Rajaa. 2008. Girls of Riyadh. London: Penguin.

Anishchenkova, V. 2014. Autobiographical identities in contemporary Arab culture. Edinburgh: Edinburgh University Press. https://doi.org/10.3366/ edinburgh/9780748643400.001.0001

Archer-Lean, C. 2009. Revisiting literary utopias and dystopias: Some new genres. Social Alternatives 28(3): 3-7.

Asl, M.P. 2019a. Leisure as a space of political practice in Middle East women life writings. GEMA Online ${ }^{\circledR}$ Journal of Language Studies 19(3): 43-56. https://doi. org/10.17576/gema-2019-1903-03

. 2018. Practices of counter-conduct as a mode of resistance in Middle East women's life writings. 3L: Language, Linguistics, Literature ${ }^{\circledR}$ 24(2): 195-205. https://doi.org/10.17576/3L-2018-2402-15

- 2019b. Foucauldian rituals of justice and conduct in Zainab Salbi's Between Two Worlds. Journal of Contemporary Iraq and the Arab World 13(2/3): 227-242. https://doi.org/10.1386/jciaw_00010_1 
Begos, K. 2017. Review: Daring to Drive illuminates Saudi woman's life. The Associated Press, 13 June. Retrieved from https://apnews.com/ c067f66dc47c4e5fb20be8f959c86c3f/Review:-\%27Daring-to-Drive\%27illuminates-Saudi-woman $\% 27 \mathrm{~s}$-life

Blunt, A. and Rose, G., eds. 1994. Writing women and space: Colonial and postcolonial geographies. New York/London: Guilford Press.

Bosch, M. 2008. Telling stories, creating (and saving) her life. An analysis of the autobiography of Ayaan Hirsi Ali. Women's Studies International Forum 31(2): 138-147. https://doi.org/10.1016/j.wsif.2008.03.006

Davis, T. 2010. Third spaces or heterotopias? Recreating and negotiating migrant identity using online spaces. Sociology 44(4): 661-677. https://doi. org/10.1177/0038038510369356

Dodge, J.J. 2015. Spaces of resistance: Heterotopia and transgression in Chuck Palahniuk's Fight Club. Lit: Literature Interpretation Theory 26(4): 318-333. https://doi.org/10 $.1080 / 10436928.2015 .1092348$

Faruqi, Saadia. 2017. A book review by Saadia Faruqi: Daring to Drive: A Saudi woman's awakening. New York Journal of Books. Retrieved from https://www. nyjournalofbooks.com/book-review/daring-drive.

Foucault, M. 1999. Space, power and knowledge. In The cultural studies reader, ed. S. During, 134-141. London: Routledge.

1986. Of other spaces. Diacritics, 16(1): 22-27. https://doi.org/10.2307/464648

-1995. Discipline and punish. Translated by A. Sheridan. New York: Vintage.

Genocchio, B. 1995. Discourse, discontinuity, difference: The question of "other" spaces. In Postmodern cities and spaces, eds. S. Watson and K. Gibson, 35-46. Oxford/ Cambridge: Blackwell.

Golley, N.A.-H. 2014. Strategically speaking: Multiple identities/hybrid narratives. Hawwa 12(2-3): 161-168. https://doi.org/10.1163/15692086-12341261 . 2003. Reading Arab women's autobiographies: Shahrazad tells her story. Texas: University of Texas Press.

Golley, N.A.-H., ed. 2007. Arab women's lives retold: Exploring identity through writing. New York: Syracuse University Press.

Haidar, Ensaf and Hoffmann, A.C. 2016. Raif Badawi, the voice of freedom: My husband, our story. London: Little, Brown.

Hamam, K. 2014. Confining spaces, resistant subjectivities: Toward a metachronous discourse of literary mapping and transformation in postcolonial women's writing. Newcastle, UK: Cambridge Scholars Publishing.

Hamdan, Amani. 2012. The role of authentic Islam: The way forward for women in Saudi Arabia. Hawwa 10(3): 200-220. https://doi.org/10.1163/15692086-12341237

Haragos, S. 2019. Selves and identities in the Arabian Gulf: The year in the Gulf cooperation council. Biography 42(1): 55-61. https://doi.org/10.1353/bio.2019.0009

Hetherington, K. 1997. The badlands of modernity: Heterotopia and social ordering. London: Routledge.

Hetland, P. 2012. Internet between utopia and dystopia: The narratives of control. Nordicom Review 33(2): 3-15. https://doi.org/10.2478/nor-2013-0010 
Johnson, P. 2006. Unravelling Foucault's "different spaces". History of the Human Sciences 19(4): 75-90. https://doi.org/10.1177/0952695106069669

Kholoussi, Samia. 2019. Arab women's autobiography: A contentious practice that elicits disapprobation, jeering, curiosity and/or ... furor. Advances in Social Sciences Research Journal 6(7): 287-309. https://doi.org/10.14738/assrj.67.6614

Laube, L. 2010. Behind the veil: An Australian nurse in Saudi Arabia. South Australia: Wakefield Press.

Leib, R.S. 2017. Spaces of the self: Foucault and Goffman on the micro-physics of discipline. Philosophy Today 61(1): 189-210. https://doi.org/10.5840/ philtoday2017321153

Lim, M. 2018. Unveiling Saudi feminism(s): Historicization, heterogeneity and corporeality in women's movements. Canadian Journal of Communication 43(3): 461-479. https://doi.org/10.22230/cjc.2019v44n3a3379

Masry, F. and Chenard, S. 2008. Running for all the right reasons: A Saudi-born woman's pursuit of democracy. New York: Syracuse University Press.

Mendola, T. 2009. Where do we go from here?: Reading “Arab Women's Writing” today. College Literature 36(3): 221-229. https://doi.org/10.1353/lit.0.0065

Mohanty, C.T. 2003. Feminism without borders: Decolonizing theory, practicing solidarity. Durham: Duke University Press. https://doi.org/10.1215/9780822384649

Moore, L. 2008. Arab, Muslim, woman: Voice and vision in postcolonial literature and film. London/New York: Routledge.

Mustafa, R.F. and Troudi, S. 2019. Saudi Arabia and Saudi women in research literature: A critical look. Asian Social Science 15(2): 133-141. https://doi.org/10.5539/ass. $\mathrm{v} 15 \mathrm{n} 2 \mathrm{p} 133$

Nash, G. 2007. The Anglo-Arab encounter: Fiction and autobiography by Arab writers in English. Bern, Switzerland: Peter Lang. https://doi.org/10.3726/978-3-0353-0419-0

Petrushevskaya, L. 2013. Secrets behind the veil: Memoirs of an expatriate woman in Saudi Arabia. Washington: Kindle Publishing.

Sassoon, J. 2016. Anatomy of authoritarianism in the Arab republics. Cambridge, UK: Cambridge University Press. https://doi.org/10.1017/CBO9781107337893

- 2014. Princess, more tears to cry. London/New York: Bantam Books.

Silverman, H.J. 1980. From utopia/dystopia to heterotopia: An interpretive topology. Philosophy and Social Criticism 7(2): 170-182. https://doi. org/10.1177/019145378000700203

Suyoufie, F. 2008. The appropriation of tradition in selected works of contemporary Arab women writers. Journal of Arabic Literature 39(2): 216-249. https://doi. org $/ 10.1163 / 157006408 X 330463$

Totah, F.M. 2017. Women in the Middle East take a stand. Anthropology News 58(3): e267-e270. https://doi.org/10.1111/AN.482

Tsujigami, N. 2018. Stealth revolution: Saudi women's ongoing social battles. In Arab women's activism and socio-political transformation, eds. S. Khamis and A. Mili, 149-166. Cham, Switzerland: Palgrave Macmillan. https://doi.org/10.1007/978-3319-60735-1_8

Vrbančić, M. 2015. Borges's postmodern landscape. CLCWeb: Comparative Literature and Culture 17(4): 1-8. https://doi.org/10.7771/1481-4374.2831 
Wolf, B. 2019. Good trouble: How deviants, criminals, heretics and outsiders have changed the world for the better. London: Lexington Books.

Zembylas, M. and Ferreira, A. 2009. Identity formation and affective spaces in conflictridden societies: Inventing heterotopic possibilities. Journal of Peace Education 6(1): 1-18. https://doi.org/10.1080/17400200802658381 